\title{
Hot Deformation and Dynamic Recrystallisation Behaviour of Twin-Roll Cast Mg-6.8Y-2.5Zn-0.4Zr Magnesium Alloy
}

\author{
Madlen Ullmann*D, Kristina Kittner and Ulrich Prahl $\mathbb{D}$ \\ Institute of Metal Forming, Technische Universität Bergakademie Freiberg, Bernhard-von-Cotta-Straße 4, \\ 09599 Freiberg, Germany; kristina.kittner@imf.tu-freiberg.de (K.K.); ulrich.prahl@imf.tu-freiberg.de (U.P.) \\ * Correspondence: madlen.ullmann@imf.tu-freiberg.de; Tel.: +49-3731-39-3095
}

Citation: Ullmann, M.; Kittner, K.; Prahl, U. Hot Deformation and

Dynamic Recrystallisation Behaviour of Twin-Roll Cast Mg-6.8Y-2.5Zn-0.4Zr Magnesium Alloy. Materials 2021, 14, 307. https://doi.org/10.3390/ ma14020307

Received: 17 November 2020 Accepted: 4 January 2021 Published: 8 January 2021

Publisher's Note: MDPI stays neutral with regard to jurisdictional clai$\mathrm{ms}$ in published maps and institutional affiliations.

Copyright: (C) 2021 by the authors. Licensee MDPI, Basel, Switzerland. This article is an open access article distributed under the terms and conditions of the Creative Commons Attribution (CC BY) license (https:// creativecommons.org/licenses/by/ $4.0 /)$.

\begin{abstract}
In this work, the deformation behaviour of a twin-roll cast (TRC) Mg-6.8Y-2.5Zn-0.4Zr alloy during plane strain compression was characterised by high-temperature testing. Based on the experimental data, the values of strain-rate sensitivity, the efficiency of power dissipation and the instability parameter were investigated under the conditions of various hot deformation parameters. In contrast to conventionally cast material, no lamellae of the LPSO (long period stacking ordered) phase were precipitated in the magnesium matrix after TRC. The precipitation of fine lamellar LPSO phases only occurred during cooling to forming temperature after the heat treatment. Dynamic recrystallization (DRX) hardly occurred during deformation at temperatures between $350{ }^{\circ} \mathrm{C}$ and $400{ }^{\circ} \mathrm{C}$. This can be attributed to the precipitation of the lamellar LSPO phases, which contribute to retardation of the DRX process. At higher deformation temperatures and strain rates DRX is pronounced and the twin-induced (TRDX) as well as continuous dynamic recrystallization could be identified as the dominant softening mechanisms. The processing maps were established by superimposing the instability map over the power dissipation map, this being associated with microstructural evolution analysis in the hot deformation processes. Two instability zones could be recognised for the twin-roll cast and heat-treated Mg-6.8Y-2.5Zn-0.4Zr alloy: (1) $350{ }^{\circ} \mathrm{C}$ to $460{ }^{\circ} \mathrm{C}$ and $0.01 \mathrm{~s}^{-1}$ to $0.3 \mathrm{~s}^{-1}$ and (2) $485^{\circ} \mathrm{C}$ to $525^{\circ} \mathrm{C}$ and $2.5 \mathrm{~s}^{-1}$ to $10 \mathrm{~s}^{-1}$, where deformation is not favourable.
\end{abstract}

Keywords: flow curve; dynamic recrystallisation; processing map; LPSO phase; Mg-6.8Y-2.5Zn-0.4Zr; twin-roll casting

\section{Introduction}

Wrought magnesium alloys of the Mg-Y-Zn alloying system are becoming increasingly important because of their high strength at both room temperature and elevated temperatures. The high strength of such alloys is attributed to the presence of long-period stacking ordered phases (LPSO), which are characterised by the fact that the basal planes are enriched with $Y$ and $\mathrm{Zn}$ at periodic intervals [1,2]. These ordered structures can have different stacking sequences: $10 \mathrm{H}[3,4], 12 \mathrm{R}[5,6], 14 \mathrm{H}[1,7,8], 18 \mathrm{R}$ [1,7-9] and 24R [10]. Investigations have shown that LPSO phases have a significant influence on hot deformation behaviour and dynamic recrystallisation. Chen et al. (2020) [11] investigate the importance of the LPSO phase in a Mg-8.02Y-1.99Zn alloy during dynamic recrystallisation under various strain conditions. They find that the alloy exhibits a flow behaviour comparable to that of conventionally available magnesium alloys, but that the LPSO phase significantly influences dynamic recrystallisation (DRX). (I) Kink deformation in LPSO phases are initiation points for DRX. (II) Fragmentation of the LPSO phase favours DRX through particle-stimulated nucleation (PSN). (III) DRX grains are also pinned by the LPSO phases at higher temperatures, and grain boundary migration is inhibited.

LPSO-containing alloys and, in particular, $\mathrm{Mg}-\mathrm{Y}-\mathrm{Zn}$ and $\mathrm{Mg}-\mathrm{Gd}-\mathrm{Zn}$ systems, have been investigated in the past to determine their hot-working behaviour [11-16]. The aim is to define parameters for hot-working processes and to understand the mechanisms involved 
in hot working and DRX. By means of compression tests in the temperature range from $300{ }^{\circ} \mathrm{C}$ to $500{ }^{\circ} \mathrm{C}$ and strain rates between $0.001 \mathrm{~s}^{-1}$ and $10 \mathrm{~s}^{-1}$, the hardening and softening behaviour of various LPSO-containing alloys was analysed and described. Based on these results, processing maps were derived that provided information on areas of stable and unstable deformation [17]. For a Mg-9Gd-2.9Y-1.9Zn-0.4Zr alloy as the initial cast material, $\mathrm{Xu}$ et al. (2016) [15] determine that $450{ }^{\circ} \mathrm{C}$ and $0.001 \mathrm{~s}^{-1}$ are optimal hot-working parameters. For a Mg-5.8Y-2.0Zn-0.3Zr alloy (wt.\%), Lv et al. (2013) [18] suggest values from $400{ }^{\circ} \mathrm{C}$ to $500{ }^{\circ} \mathrm{C}$ and $0.001 \mathrm{~s}^{-1}$ to $0.01 \mathrm{~s}^{-1}$ as well as $500{ }^{\circ} \mathrm{C}$ and $0.1 \mathrm{~s}^{-1}$ to $1 \mathrm{~s}^{-1}$ as optimal hot-working conditions. It is common to all investigations carried out so far that conventionally cast or extruded starting material was examined. However, twin-roll cast strips of LPSO-containing magnesium alloys have not been considered to date. Twin-roll casting enables the production of magnesium strips in an economic and energy-efficient way. Over the past 25 years, intensive research has been conducted on TRC of magnesium alloys and the process has been transferred to industrial production. The most common magnesium alloy AZ31 is well investigated. However, the area of application is limited due to their poor performance at elevated temperatures. The twin-roll casting of the Mg-6.8Y$2.5 \mathrm{Zn}-0.4 \mathrm{Zr}$ alloy offers the possibility to provide strips of a high strength and thermally stable magnesium alloy. Due to the special solidification conditions and the resulting microstructural changes involved, the hot-working behaviour of other initial conditions cannot be assigned to the TRC state. Accordingly, the aim of this work was to investigate the hot working behaviour of a twin-roll cast Mg-6.8Y-2.5Zn- $0.4 \mathrm{Zr}$ alloy. As a function of the forming temperature and strain rate, flow curves were recorded and, based on these data, the dynamic recrystallisation behaviour was described. Furthermore, process maps were derived which were then used to provide optimal parameters for hot working of the twin-roll cast and heat-treated Mg-6.8Y-2.5Zn-0.4Zr alloy.

\section{Materials and Methods}

The chemical composition of the Mg-6.8Y-2.5Zn-0.4Zr alloy is shown in Table 1. Details on the production of twin-roll cast strips of $\mathrm{Mg}-6.8 \mathrm{Y}-2.5 \mathrm{Zn}-0.4 \mathrm{Zr}$ alloy are described in detail in [19].

Table 1. Chemical composition of Mg-6.8Y-2.5Zn-0.4Zr (wt.\%) alloy as determined by means of optical emission spectrometry (OES).

\begin{tabular}{ccccccccc}
\hline $\mathbf{Y}$ & $\mathbf{Z n}$ & $\mathbf{Z r}$ & $\mathbf{S i}$ & $\mathbf{F e}$ & $\mathbf{C u}$ & $\mathbf{N i}$ & Others & $\mathbf{M g}$ \\
\hline 6.8 & 2.5 & 0.4 & 0.01 & 0.005 & 0.001 & 0.001 & 0.01 & Balance \\
\hline
\end{tabular}

With a length of $20 \mathrm{~mm}$ and a width of $30 \mathrm{~mm}$, samples for compression tests were cut from the twin-roll cast sheets (sheet thickness $5.3 \mathrm{~mm}$ ). Subsequently, plane strain compression tests were performed on a servo-hydraulic hot-working simulator. A graphite-oil mixture was used as a lubricant to reduce the friction between the punch and sample. Before compression, the samples were heat treated at $500^{\circ} \mathrm{C}$ for $2 \mathrm{~h}$. While taking into account friction and dissipation heat, isothermal flow curves were determined from the recorded force-displacement data. In addition, the flow curves were corrected according to Siebel with a coefficient of friction of $\mu=0.12$. Furthermore, softening processes due to the temperature increase as a result of the dissipated forming energy were considered numerically by the thermodynamic temperature factor $K_{\vartheta}=\exp \left(-m_{1} \times \vartheta\right)$, with $m_{1}=-0.00427^{\circ} \mathrm{C}^{-1}$. The forming temperature $\left(350-525^{\circ} \mathrm{C}\right)$ was set by means of an air circulation furnace and maintained for $15 \mathrm{~min}$ to ensure the uniform temperature distribution in the sample. Afterwards, continuous compression was performed at strain rates of $0.01 \mathrm{~s}^{-1}, 0.1 \mathrm{~s}^{-1}$, $1 \mathrm{~s}^{-1}$ and $10 \mathrm{~s}^{-1}$. The samples were deformed to an equivalent logarithmic strain of $\varphi_{v}=1$. At least three tests were performed for each forming condition to ensure a sufficient level of statistical certainty. Immediately after compression, the samples were quenched in water and metallographically prepared for microstructural analysis. All metallographic 
samples were made as longitudinal sections across the cross-section of the twin-roll cast strip. To this end, the samples were ground and then polished with an oxide polishing suspension. Etching was carried out in two steps. After brief rinsing with a 3\% initial solution, the sample was etched with a picric acid solution consisting of $70 \mathrm{~mL}$ ethanol, $10 \mathrm{~mL}$ distilled water, $10 \mathrm{~mL}$ glacial acetic acid and $4.2 \mathrm{~g}$ picric acid.

Microstructural analysis was carried out on the compressed and quenched samples at specific locations where the local comparative logarithmic strain corresponded to the total equivalent logarithmic strain. Light microscopic images were taken on a Keyence VHX 6000 microscope at the Institute of Metal Forming, Freiberg, Germany. Based on these images, the recrystallised portion was determined by means of point analysis. Scanning electron microscopic evaluation was then performed on a ZEISS GeminiSEM 450 device at the Institute of Metal Forming, Freiberg, Germany.

Processing maps are based on dynamic material models (DMM) and are used to optimise the hot-deformation parameters. The principles for creating processing maps can be found in [20] and [21], among others. The method takes into account the opposing relationship between the rate of heat generation induced by the forming process and the rate of energy dissipation. The microstructural changes in the structure such as recovery and dynamic recrystallisation as well as material damage are considered. Kocks-Mecking plot was used to describe the dynamic recrystallisation during hot deformation. For each flow curve the strain hardening $\theta=\delta k_{f} / \delta \varphi$ or $\theta=\Delta k_{f} / \Delta \varphi$ is plotted of the flow stress $k_{f}$. Further details of the determination of the critical stress $k_{f c}$ and the associated critical strain $\varphi_{c}$ are given in [22]. The dynamically recrystallised fraction is determined for each set of flow curves (the determined flow curve and the calculated curve for dynamic recovery) [22] according to Equation (1), where $k_{f} D R X s s$ is the stationary flow stress and $\varphi_{\text {ss }}$ the corresponding equivalent strain.

$$
X_{d y n}=\frac{k_{f D R V}(\varphi)-k_{f D R X}(\varphi)}{k_{f D R V s s}-k_{f D R X s s}} .
$$

\section{Results and Discussion}

\subsection{Microstructure of Twin-Roll Cast and Heat-Treated Alloy}

Figure 1 shows the microstructure of the twin-roll cast Mg-6.8Y-2.5Zn-0.4Zr alloy after heat treatment at $500{ }^{\circ} \mathrm{C}$ for $2 \mathrm{~h}$. The microstructure after twin-roll casting consisted primarily of $\alpha$-magnesium matrix material, which was pervaded by a fine network of LPSO phases. A detailed description of the microstructural composition and the texture of twin-roll cast strips of Mg-6.8Y-2.5Zn-0.4Zr alloy can be found in [19]. On the basis of X-ray diffraction investigations, the LPSO phases that occurred after twin-roll casting could be assigned to the $18 \mathrm{R}$ or $14 \mathrm{H}$ structures. In comparison to the initial cast material, one significant difference in the microstructural composition of the TRC strips was that in addition to the $\alpha$-magnesium matrix and the network-like LPSO phase within the matrix, fine lamellar LPSO phases did not occur. After heat treatment at $500{ }^{\circ} \mathrm{C}$ with a holding time of $2 \mathrm{~h}$, no changes could be observed in the material's microstructural composition. The network-like LPSO phases remained intact. Higher temperatures $\left(525^{\circ} \mathrm{C}\right)$ and/or longer holding times $(6 \mathrm{~h})$ are required to dissolve such phases [19].

\subsection{Flow Behaviour}

Figure 2 summarises the flow curves of the twin-roll cast and heat-treated $\mathrm{Mg}-6.8 \mathrm{Y}-$ $2.5 \mathrm{Zn}-0.4 \mathrm{Zr}$ alloy for a temperature range from $350{ }^{\circ} \mathrm{C}$ to $500{ }^{\circ} \mathrm{C}$ and strain rates of $0.01 \mathrm{~s}^{-1}$, $0.1 \mathrm{~s}^{-1}, 1 \mathrm{~s}^{-1}$ and $10 \mathrm{~s}^{-1}$. It is clear that the hardening and softening behaviour was dependent on both the forming temperature and the strain rate. The results shown here are typical flow curves for the occurrence of dynamic recrystallisation during hot working [23]. With increasing the strain rate and decreasing temperature, an increase in yield strength could be observed. This phenomenon was associated with the fact that the rate of dislocation multiplication increases with increasing the strain rate, the dislocation movement 
is stopped and, consequently, the yield strength is increased. After the increase of the flow stress in the course of hardening, which was caused by the increase in dislocation density, the flow curves exhibited different progressions depending on the temperature up to the yield stress maximum. From temperatures of $450{ }^{\circ} \mathrm{C}$, the flow stress decreased continuously after reaching the maximum. The decrease in flow stress could be attributed here to the occurrence of dynamic recrystallisation. High temperatures $\left(500{ }^{\circ} \mathrm{C}\right)$ or low strain rates $\left(0.01 \mathrm{~s}^{-1}\right)$ achieved the steady state range in the equivalent strain range under consideration (equivalent strain to 1 ). This meant that complete dynamic recrystallisation had taken place.

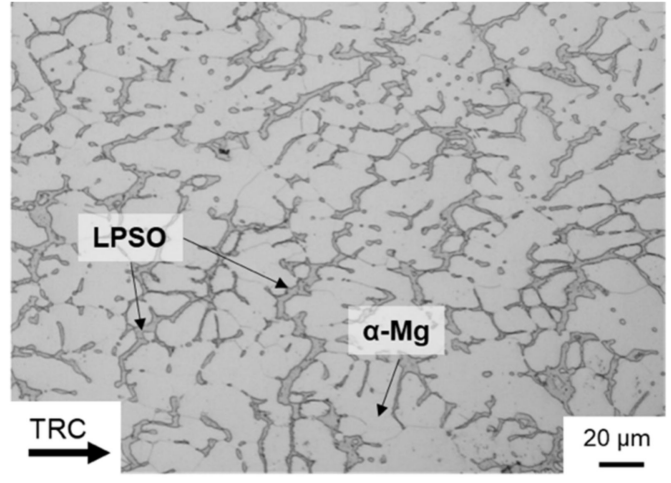

(a)

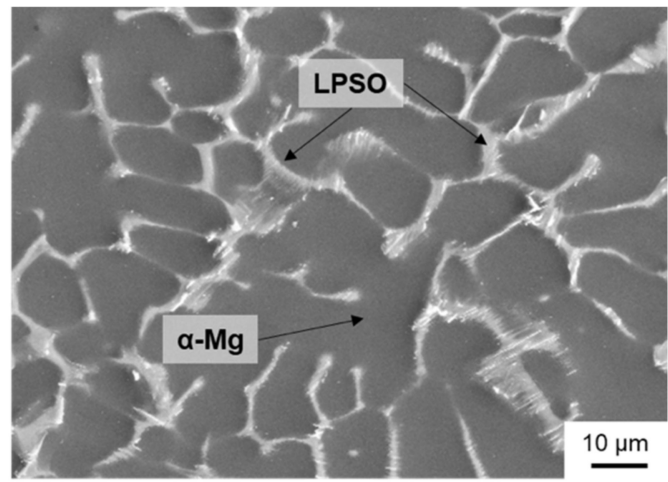

(b)

Figure 1. (a) Optical and (b) SEM micrographs (SE, $15 \mathrm{kV}$ ) of the twin-roll cast and heat-treated $\left(500{ }^{\circ} \mathrm{C}, 2 \mathrm{~h}\right) \mathrm{Mg}-6.8 \mathrm{Y}-2.5 \mathrm{Zn}-0.4 \mathrm{Zr}$ alloy.

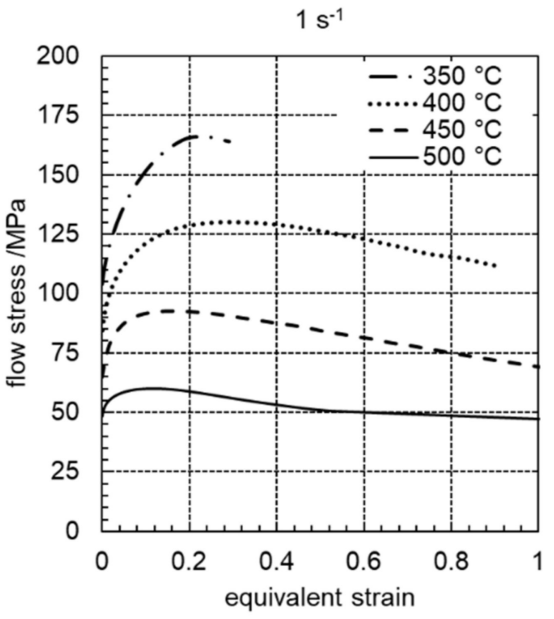

(a)

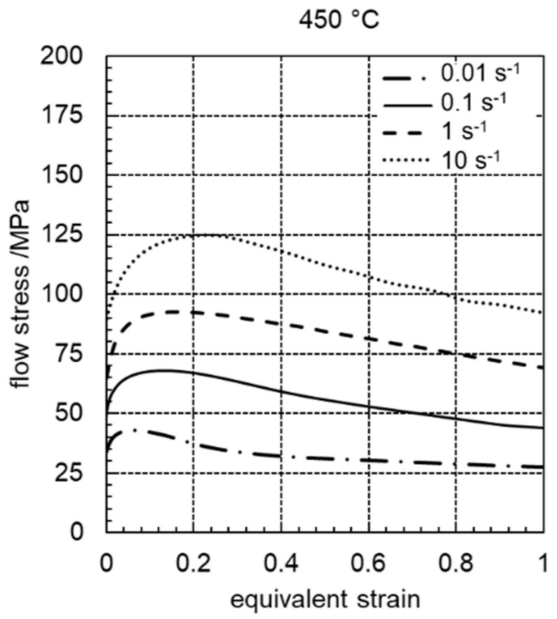

(b)

Figure 2. Flow curves of the twin-roll cast and heat-treated Mg-6.8Y-2.5Zn-0.4Zr alloy: (a) temperature range between $350{ }^{\circ} \mathrm{C}$ and $500{ }^{\circ} \mathrm{C}$ for a strain rate of $1 \mathrm{~s}^{-1}$ and (b) for different strain rates of $0.01 \mathrm{~s}^{-1}, 0.1 \mathrm{~s}^{-1}, 1 \mathrm{~s}^{-1}$ and $10 \mathrm{~s}^{-1}$ at $450{ }^{\circ} \mathrm{C}$.

Softening processes could hardly be observed at low forming temperatures $\left(350^{\circ} \mathrm{C}\right)$. Here, the flow stress increased continuously because of the increasing hardening. Only a slight decrease of the flow stress can be found after reaching peak stress, which points to the occurrence of softening processes. Flow instabilities caused premature material failure through the occurrence of cracks. Comparable hardening and softening behaviour is determined for a cast Mg-6.8Y-2.5Zn-0.4Zr alloy in [21]. However, comparison with the material investigated in the current study clearly shows that dynamic recrystallisation in the case of the twin-roll cast and heat-treated Mg-6.8Y-2.5Zn-0.4Zr alloy already commenced at lower temperatures. In addition to an earlier onset of DRX (low critical degree of 
deformation), the results in Figure 2 show that DRX was more likely to have been completed than would be the case for a conventionally cast initial material [21]. It was assumed that DRX was favoured in the twin-roll cast and heat-treated Mg-6.8Y-2.5Zn-0.4Zr alloy. In contrast to the conventionally cast initial material, there were no lamellae precipitated in the magnesium matrix in the twin-roll cast and heat-treated initial state. As already shown in [24], such lamellae can contribute to the delay of the DRX process.

\subsection{Analysis of Hot Deformation Behaviour of Twin-Roll Cast and Heat-Treated Mg-6.8Y-2.5Zn-0.4Zr Alloy}

For the evaluation of the efficiency index $\eta$ and the instability parameter $\xi(\dot{\varepsilon})$ as a function of the forming temperature, the logarithmic strain and the comparative strain rate in the process charts, the characteristics of the plastic flow were calculated based on the hot flow curves determined. The mechanisms during hot working were derived based on Equation (2) according to Sellars and Tegart [25,26].

$$
\dot{\varepsilon}=A[\sinh (\alpha \sigma)]^{n} \exp \left(-\frac{Q}{R \cdot T}\right)
$$

The equation takes into account the strain rate $\dot{\varepsilon}$, the material constant $A$ at $2.617 \times 10^{19} \mathrm{~s}^{-1}$, $n$ as the creep and stress exponent at 7.487, $\alpha$ as the coefficient of adaptation at $0.0108 \mathrm{MPa}^{-1}$, $\sigma$ as the maximum stress, $Q$ as the average activation energy for plastic flow at $270.63 \mathrm{~kJ} / \mathrm{mol}$, the gas constant $R$ at $8.314 \mathrm{~J} /(\mathrm{mol} \mathrm{K})$ and $T$ as the thermodynamic forming temperature. The parameters of the equation were determined using the mean values from the increases in the graphs, which represented the linear relationship of the flow stress to the comparative strain rate and temperature (Figure 3 ). The calculated model coefficients were valid for forming temperatures of between $350{ }^{\circ} \mathrm{C}$ and $500{ }^{\circ} \mathrm{C}$ and for comparative strain rates of between $0.01 \mathrm{~s}^{-1}$ and $10 \mathrm{~s}^{-1}$. The calculation was based on the assumption that the processes taking place during forming were diffusion controlled. Accordingly, all model coefficients were temperature- and strain rate-dependent.

The activation energy is a measure of the difficulty of initiating deformations during hot working, and is simultaneously influenced by the dynamic precipitation formation, the pinning effects of dislocations and the occurrence of secondary phases. For cast magnesium alloys with LPSO phases, the activation energy varies between $182 \mathrm{~kJ} / \mathrm{mol}$ and $276 \mathrm{~kJ} / \mathrm{mol}$ [27]. The value determined for the twin-roll cast and heat-treated $\mathrm{Mg}$ $6.8 \mathrm{Y}-2.5 \mathrm{Zn}-0.4 \mathrm{Zr}$ alloy was in the upper range at $270 \mathrm{~kJ} / \mathrm{mol}$, which was significantly higher than that for grain boundaries $(92 \mathrm{~kJ} / \mathrm{mol})$ or lattice diffusions $(135 \mathrm{~kJ} / \mathrm{mol})$ in magnesium $[28,29]$. The higher value for the activation energy was likely associated with the increased proportion of LPSO phases. These impede dislocation movement during deformation and cause self-diffusion within the crystal lattice to be suppressed [2,30,31].

The model coefficients determined were also used to calculate the Zener-Hollomon parameter Z (Equation (3)).

$$
Z=\dot{\varepsilon} \exp \left(\frac{Q}{R T}\right)
$$

As a function of $Z$ and $\ln [\sinh (\alpha \sigma)]$ the power-law relationship is investigated. The linear regression was determined at low $Z$ values with an accuracy of $\left(R^{2}\right)=0.99$, resulting in a good approximation of the hyperbolic sine function. According to the constitutive equation (Equation (4))

$$
Z=A \sin h^{n}(\alpha \sigma)
$$

The stress exponent $n$ amount to 7.487. The fitting parameter $\alpha=0.0108 \mathrm{MPa}^{-1}$ can be determined from the diagram in Figure $4 \mathrm{a}$. In the characteristic hyperbolic sine function, as expected, there is an improved degree of linearity compared to the curves seen in Figure $4 \mathrm{~b}$. 


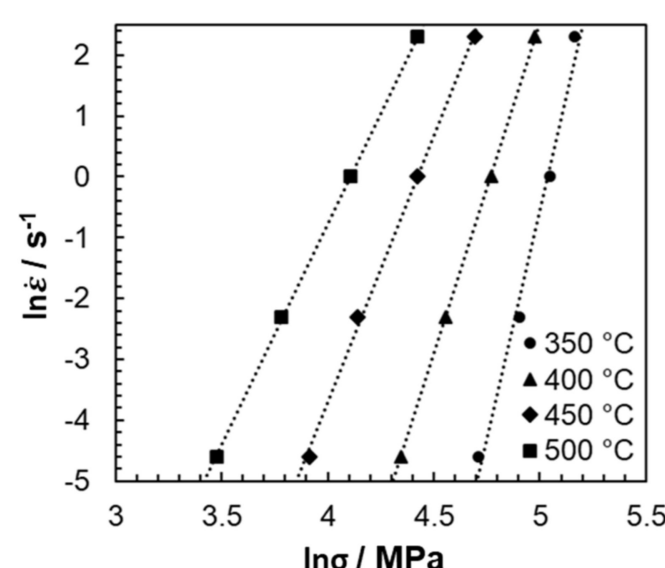

(a)

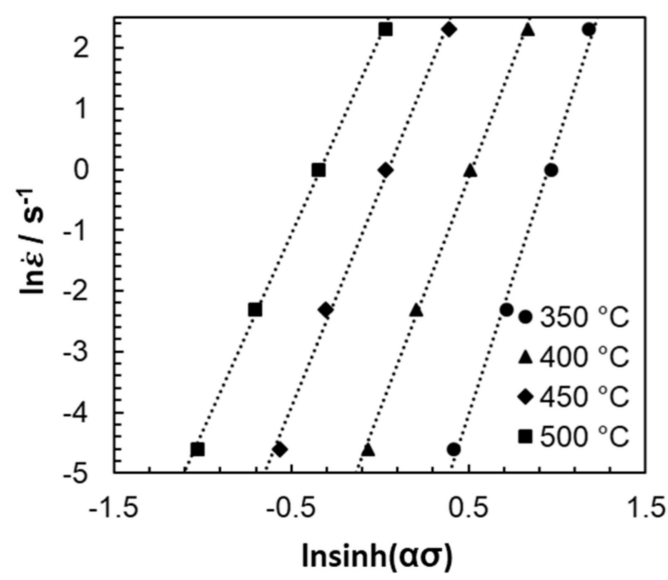

(c)

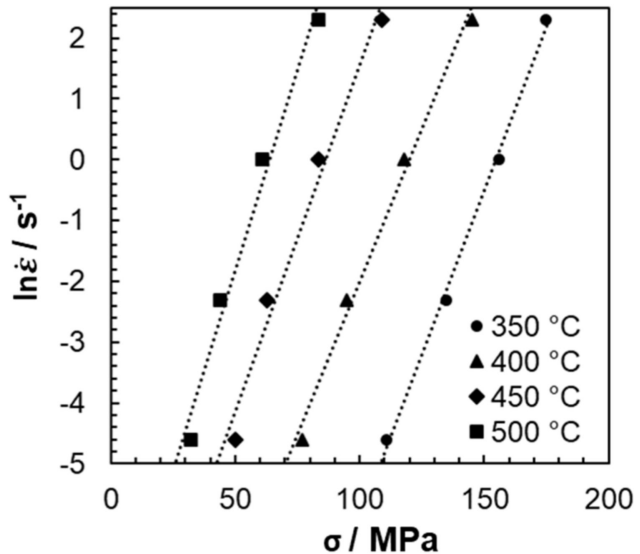

(b)

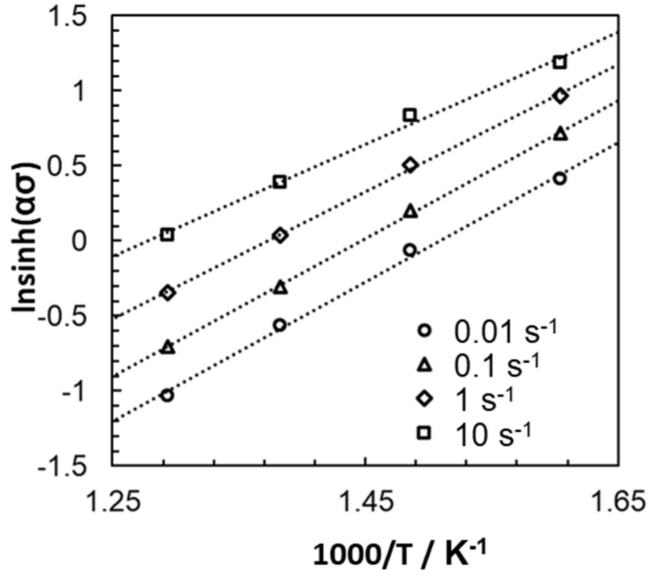

(d)

Figure 3. Relationship between $\ln (\dot{\varepsilon})$ and (a) $\ln \sigma$ and (b) $\sigma$ as a function of the forming temperature as well as (c) $\ln (\dot{\varepsilon})$ and $\ln [\sinh (\alpha \sigma)]$ at different forming temperatures and $(\mathbf{d}) \ln (\sinh (\alpha \sigma)]^{-1} / T$ as a function of the strain rate.

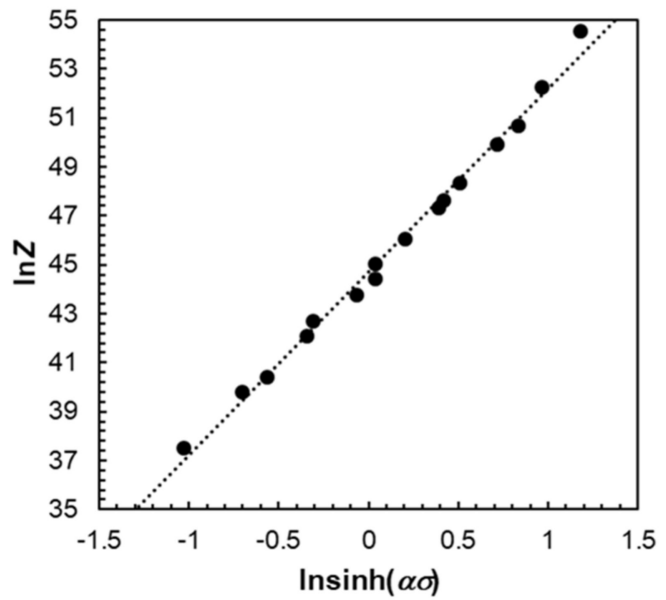

(a)

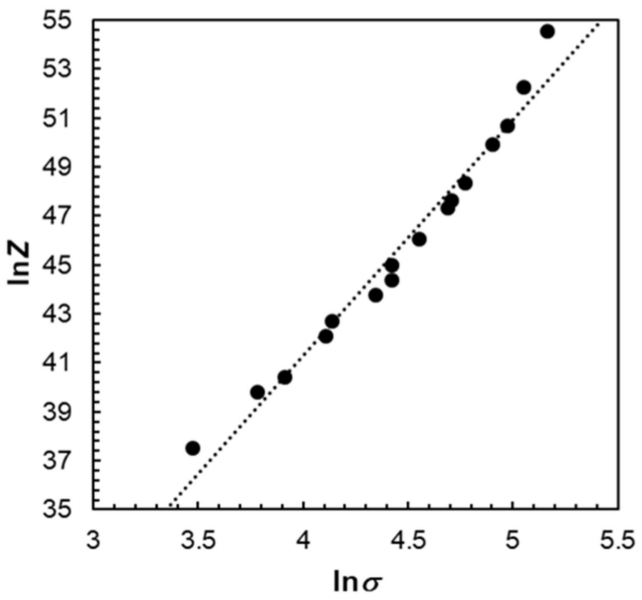

(b)

Figure 4. Relationship between the Zener-Hollomon-Parameter and the maximum stress during deformation at high temperatures: (a) $\ln Z-\ln [\sinh (\alpha \sigma)]$ and (b) $\ln Z-\ln \sigma$. 


\subsection{DRX Behaviour of Twin-Roll Cast and Heat-Treated Mg-6.8Y-2.5Zn-0.4Zr Alloy}

Figure 5 shows light microscopic images of the Mg-6.8Y-2.5Zn- $0.4 \mathrm{Zr}$ alloy after plane strain compression at $400{ }^{\circ} \mathrm{C}$ and $500{ }^{\circ} \mathrm{C}$ at a strain rate of $1 \mathrm{~s}^{-1}$ and an equivalent strain of 1 . Because of the cooling from a heat-treatment temperature of $500{ }^{\circ} \mathrm{C}$ to a forming temperature of $400{ }^{\circ} \mathrm{C}$, fine lamellae precipitated within the $\alpha$-magnesium matrix (Figure 5a). Dynamic recrystallisation hardly occurred during forming at $400{ }^{\circ} \mathrm{C}$, so that even at an equivalent strain of 1 , only a small proportion of recrystallised grains could be observed. One possible reason for this was the precipitation of lamellar LPSO phases (Figure 6b), which contribute to retardation of the DRX process [24]. In contrast, an almost completely recrystallised microstructure was present after forming at $500{ }^{\circ} \mathrm{C}$ (Figure $5 \mathrm{~b}$ ). Lamellar precipitations do not occur under these forming conditions (Figure 6c), so that suppression of the dynamic recrystallisation processes was not to be expected.

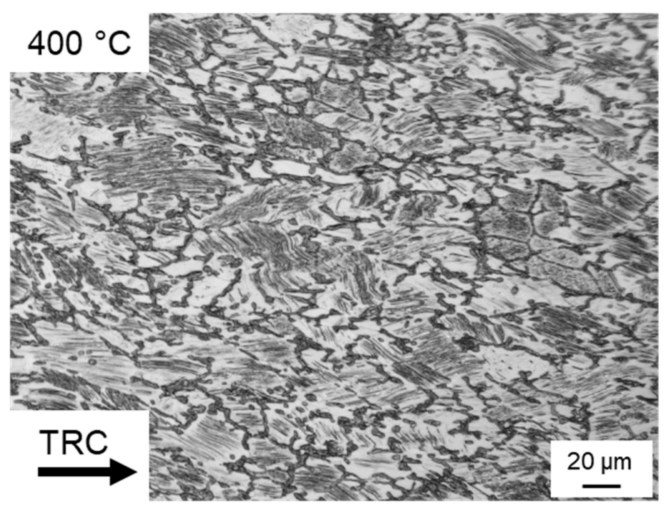

(a)

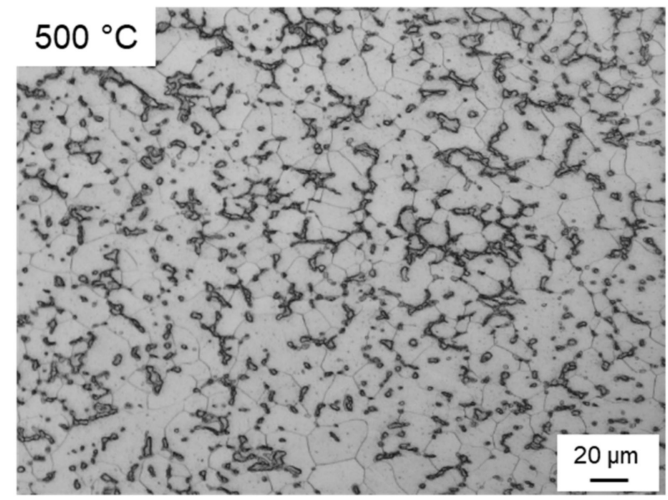

(b)

Figure 5. Light microscopic images after plane strain compression at a strain rate of $1 \mathrm{~s}^{-1}$ and an equivalent strain of 1 : (a) $400{ }^{\circ} \mathrm{C}$ and (b) $500{ }^{\circ} \mathrm{C}$.

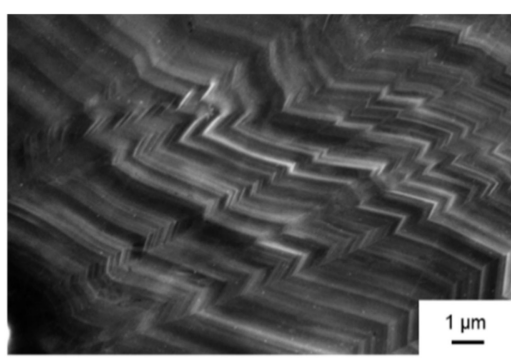

(a)

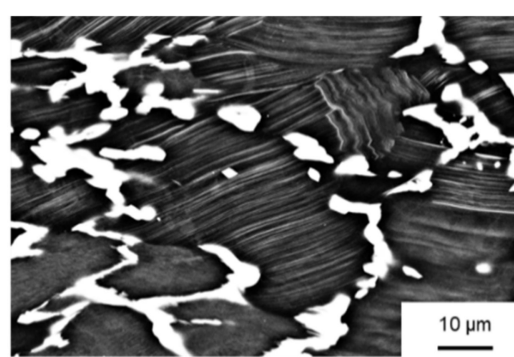

(b)

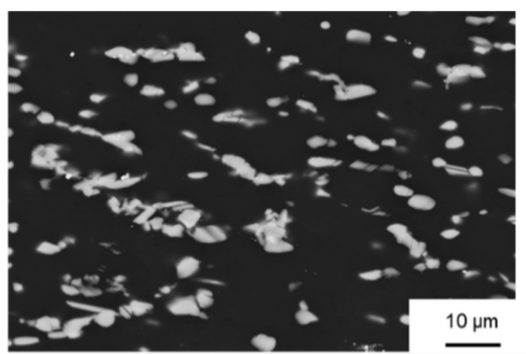

(c)

Figure 6. SEM microscopic images after plane strain compression at a strain rate of $1 \mathrm{~s}^{-1}$ and an equivalent strain of 1 : (a) kink band formation of the lamellar LPSO phase at $350{ }^{\circ} \mathrm{C},(\mathbf{b})$ at $350{ }^{\circ} \mathrm{C}$ showing lamellar LPSO phase and (c) at $500{ }^{\circ} \mathrm{C}$ without lamellar LPSO phase (BSD, $20 \mathrm{kV})$.

The observations from the microstructural analysis were confirmed by comparison of the recrystallised portions as a function of the forming temperature (Figure 7a) and the strain rate (Figure $7 \mathrm{~b}$ ). The kinetics of DRX can predict the evolution of the microstructure and volume fraction of DRX in terms of S-curves, which is usually expressed by an Avrami equation. The kinetics of DRX evolutions for the investigated alloy is expressed as (Equation (5)):

$$
X_{d y n}=1-\exp \left[-1.68 \cdot\left(\frac{\varphi-\varphi_{c}}{\varphi_{0.5}-\varphi_{c}}\right)^{2.1}\right]
$$

where $X_{d y n}$ is the dynamic recrystallisation integral, $\varphi$ is strain, $\varphi_{c}$ is the critical strain and $\varphi_{0.5}$ is the strain at a recrystallised fraction of $50 \%$. 


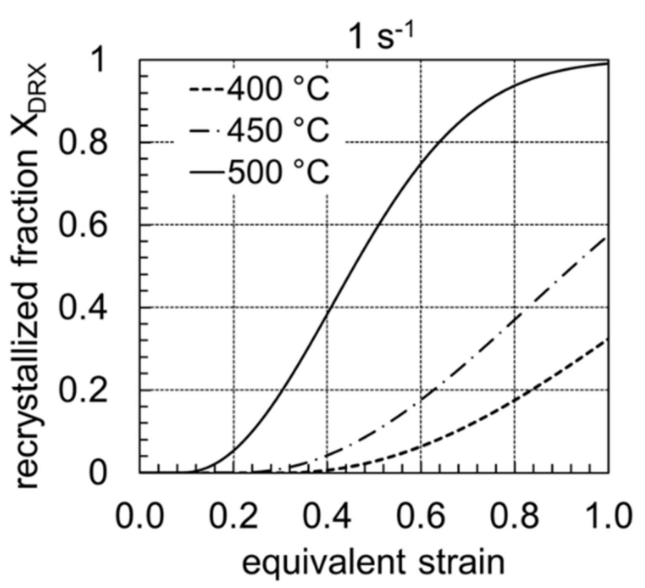

(a)

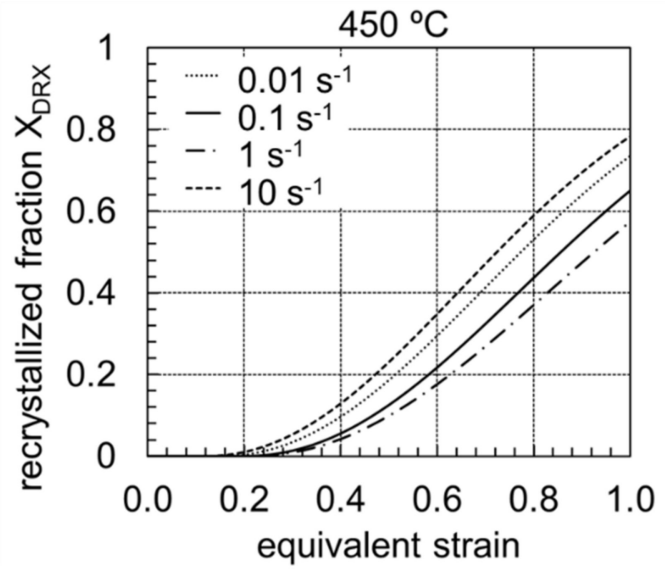

(b)

Figure 7. DRX volume fraction of twin-roll cast and heat-treated Mg-6.8Y-2.5Zn-0.4Zr alloy at (a) a strain rate of $1 \mathrm{~s}^{-1}$ and different temperatures and (b) a temperature of $450{ }^{\circ} \mathrm{C}$ and different strain rates.

On the basis of the kinetics of DRX, the effects of deformation temperature, strain and strain rate on the DRX volume fraction are shown in Figure 6. It can be seen that the deformation strain required for the same amount of DRX volume fraction increases with decreasing the deformation temperature for a strain rate of 0.01 to $10 \mathrm{~s}^{-1}$, which means that DRX was delayed to a longer time period at a lower deformation temperature. In contrast, there was no clear dependence on the strain rate, which was attributed to the change of the DRX mechanism in association with the LPSO phases. The mechanism of DRX and microstructural evolution at different deformation temperatures and strain rates is discussed in part.

Comparison of the recrystallised portion between the forming temperatures $400{ }^{\circ} \mathrm{C}$ and $500{ }^{\circ} \mathrm{C}$ (at a strain rate of $1 \mathrm{~s}^{-1}$ ) clearly showed that much higher equivalent strains were required to achieve the same recrystallised portions at $400{ }^{\circ} \mathrm{C}$. At an equivalent strain of 1 , the sample formed at $500{ }^{\circ} \mathrm{C}$ exhibited an almost completely recrystallised microstructure. At $400{ }^{\circ} \mathrm{C}$, the recrystallised portion lay at approx. $30 \%$. It was therefore assumed that higher temperatures favoured dynamic recrystallisation. As an example, Figure $6 \mathrm{~b}$ shows the influence of the strain rate on the recrystallised portion for a forming temperature of $450{ }^{\circ} \mathrm{C}$. It becomes clear that the higher the strain rate in the range of $0.01 \mathrm{~s}^{-1}$ to $1 \mathrm{~s}^{-1}$, the higher the equivalent strain required to achieve a certain recrystallised portion. At a strain rate of $0.01 \mathrm{~s}^{-1}$, for example, a $50 \%$ recrystallised microstructure is achieved at an equivalent strain of 0.75 , and at $1 \mathrm{~s}^{-1}$ only at 0.9 . For example, comparable results are reported for conventionally cast initial material by Kwak et al. (2015) [32] for a Mg5Y-2.5Zn-1.2Ca alloy and by Lv et al. (2014) [33] for a Mg-5.8Y-2.0Zn-0.3Zr alloy. Higher strain rates $\left(10 \mathrm{~s}^{-1}\right)$ cause the DRX process to accelerate. A degree of deformation of 0.7 is sufficient for the production of a $50 \%$ recrystallised microstructure.

Comparison of the light microscopic images in Figure 8 shows the extent of dynamic recrystallisation as a function of the strain rate in the range of $0.01 \mathrm{~s}^{-1}$ to $10 \mathrm{~s}^{-1}$ at a forming temperature of $450{ }^{\circ} \mathrm{C}$ and an equivalent strain of 1 . The dependence of the recrystallised portion on the strain rate can also be observed here. Many small recrystallised grains are visible at a strain rate of $0.01 \mathrm{~s}^{-1}$, the proportion of which amounts to as much as $80 \%$. With increasing strain rates of up to $1 \mathrm{~s}^{-1}$, this percentage drops to $65 \%$ and increases again to a recrystallised portion of $80 \%$ at high strain rates of $10 \mathrm{~s}^{-1}$. 


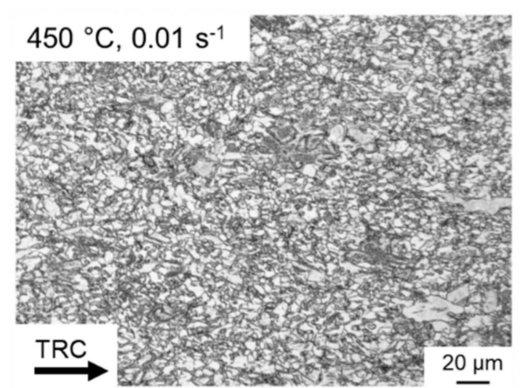

(a)

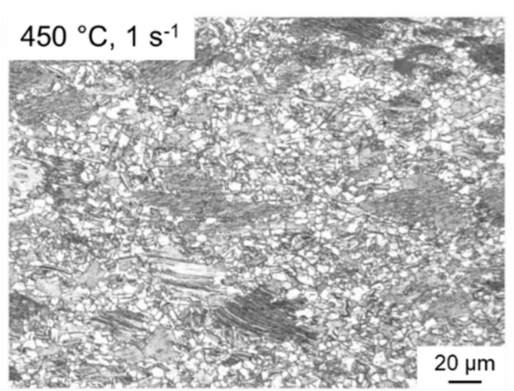

(b)

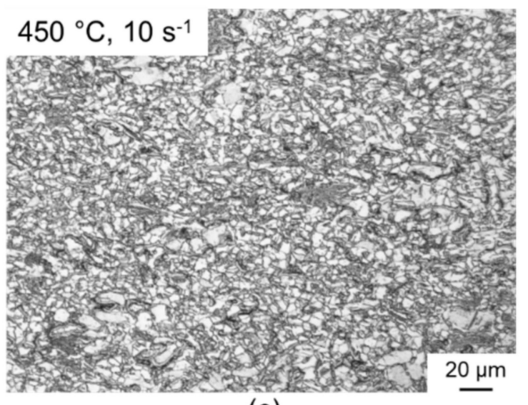

(c)

Figure 8. Optical micrographs of samples deformed at $450{ }^{\circ} \mathrm{C}$ at different strain rates: (a) $0.01 \mathrm{~s}^{-1}$, (b) $1 \mathrm{~s}^{-1}$ und (c) $10 \mathrm{~s}^{-1}$.

\subsection{The Mechanism of DRX}

Because of the high thermal stability of the network-like LPSO phases and the precipitation of fine lamellar LPSO phases (Figure 6b) during cooling to the forming temperature, the forming process and the mechanisms of dynamic recrystallisation are strongly influenced by the different LPSO phases. Figure 9a shows the microstructure after forming at $350{ }^{\circ} \mathrm{C}$. Because of the high differential between the heat-treatment and forming temperatures, fine lamellar LPSO phases precipitate in the grains of the magnesium matrix during cooling. The onset of dynamic recrystallisation could be observed locally, and was favoured along twins or at the grain boundaries of the original microstructure. Only a slight decrease in flow stress could be observed in the course of the flow curve (Figure 2a). Therefore, it was assumed that it was mainly the hardening processes that occurred. In addition, kink deformation of the LPSO phase occurred (Figure 6a), as shown in Figure $9 \mathrm{~b}$ at $400^{\circ} \mathrm{C}$. At low forming temperatures, kink band formation accounted for the majority of the plastic deformation [14]. A forming temperature of $350{ }^{\circ} \mathrm{C}$ was too low, so that nucleation of DRX was suppressed. With a low DRX content, however, this sample exhibited high levels of flow stress, with a maximum of $170 \mathrm{MPa}$. For a Mg-5.8Y-2.0Zn-0.3Zr alloy, Lv et al. (2014) [33] show that even at low strain rates, which have a more favourable effect on the recrystallisation behaviour-hardly any areas of dynamic recrystallisation can be detected at $350{ }^{\circ} \mathrm{C}$.

Figure $9 \mathrm{~b}, \mathrm{c}$ shows the microstructure after forming at $400{ }^{\circ} \mathrm{C}$ and $450{ }^{\circ} \mathrm{C}$, respectively. Kink deformation of the LPSO phase can also occur here because of the high proportion of lamellar LPSO phases within the grains of the magnesium matrix. Dynamic recrystallisation could be observed in this temperature range at kink boundaries (Figure 9b) and grain boundaries of the original microstructure (Figure 9c). To determine the origin of the dynamic recrystallisation, samples with a low degree of deformation $(\varphi=0.4)$ were compressed at $450{ }^{\circ} \mathrm{C}$ and analysed by light microscopy (Figure 10). It was found that the nucleation of dynamic recrystallisation at low equivalent strains starts preferentially at twins (Figure 10a) and in grains with lamellae that were plastically deformed by kink deformation (Figure 10b). Thus, several mechanisms of dynamic recrystallisation during forming of the twin-roll cast and heat-treated Mg-6.8Y-2.5Zn- $0.4 \mathrm{Zr}$ strip could be identified. Nucleation occurred primarily at twin boundaries (twin-induced dynamic recrystallisation, TDRX). Occasionally, DRX occurred at the grain boundaries of the original microstructure, resulting in the characteristic necklace structure during continuous dynamic recrystallisation (CDRX). The network-like LPSO phases, which were present along the original grain boundaries of the magnesium grains, impeded dislocation movement during forming such that an increase in dislocation density and, thus, in stress concentration occurred, and in particular at grain boundaries. Regions not affected by DRX were present within these grains. When the lamellar LPSO phase occurs, CDRX is mainly considered to be a recrystallisation mechanism [14,33,34]. In the present investigations, however, TDRX and DRX were increasingly observed at kink boundaries. The influence of kink deformation and DRX at kink boundaries decreased continuously with increasing forming tempera- 
tures, since the proportion of lamellar LPSO phases decreases with increasing temperature. This mechanism disappears completely at $500{ }^{\circ} \mathrm{C}$, since no lamellar LPSO phases occur.

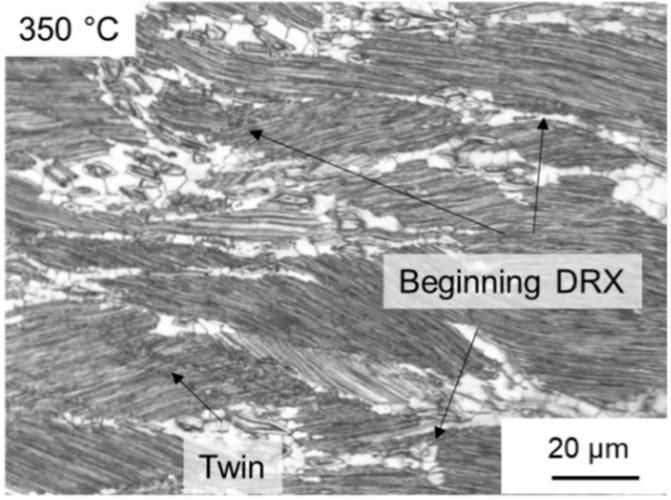

(a)

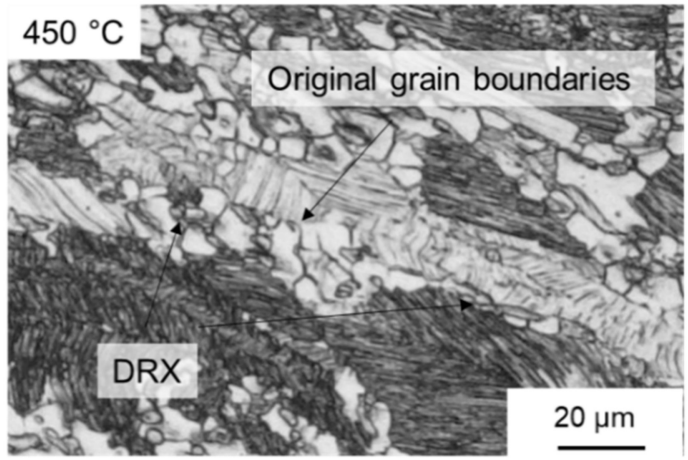

(c)

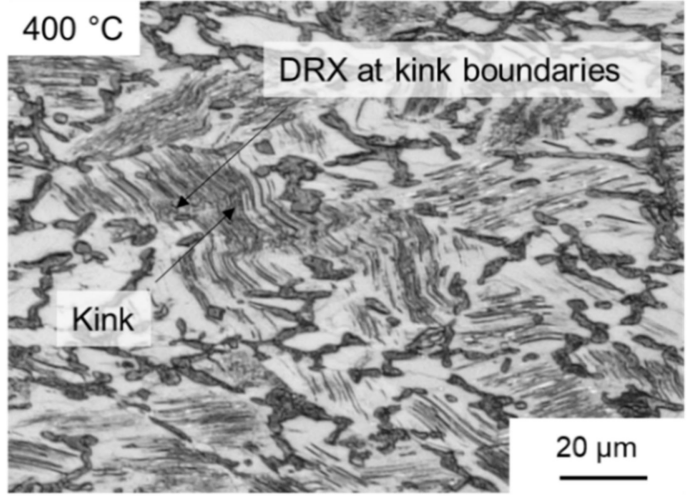

(b)

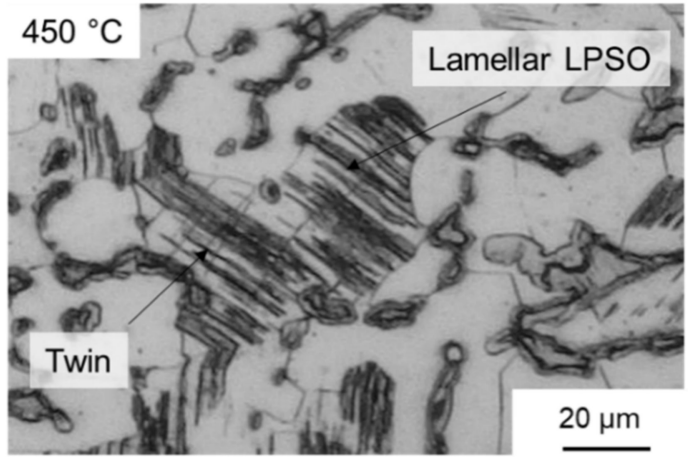

(d)

Figure 9. Optical micrographs of samples deformed at different temperatures and strain rates: (a) $350{ }^{\circ} \mathrm{C}$, (b) $400{ }^{\circ} \mathrm{C}$, (c) $450{ }^{\circ} \mathrm{C}$, DRX at original grain boundaries and (d) $450{ }^{\circ} \mathrm{C}$, twins together with lamellar LPSO phase.

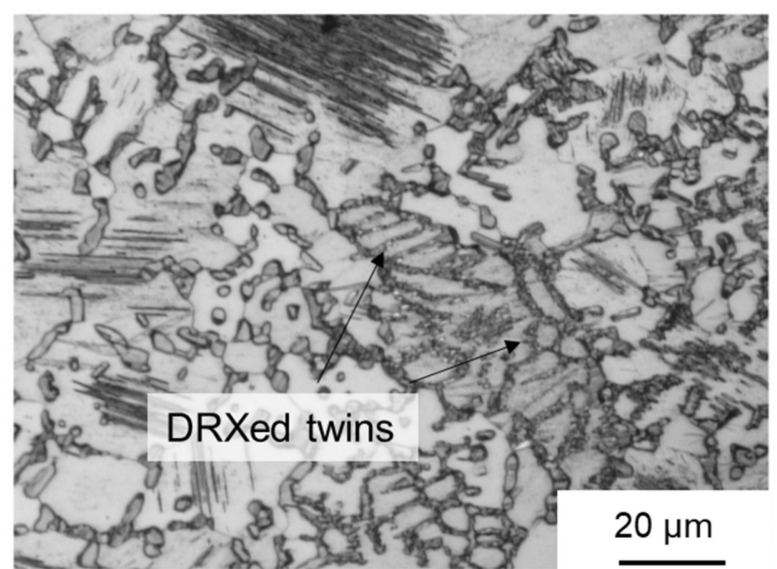

(a)

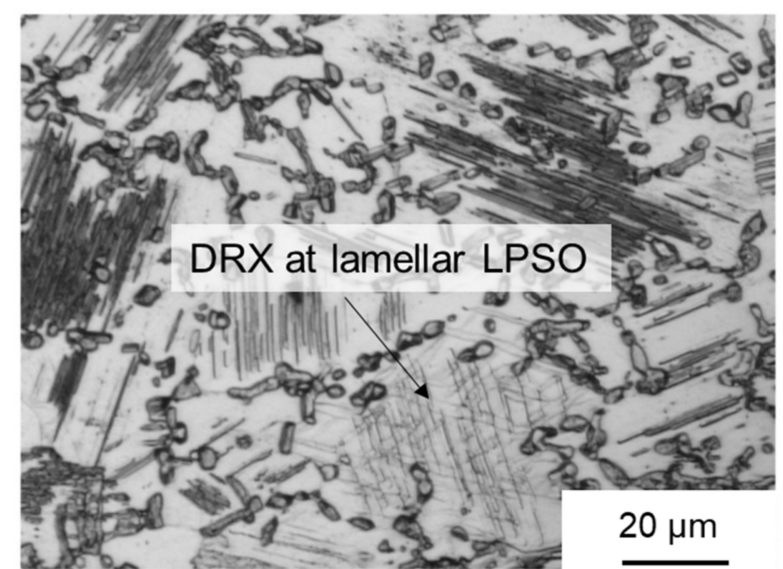

(b)

Figure 10. Optical micrographs of deformed samples at $450{ }^{\circ} \mathrm{C}$ at an equivalent strain of 0.4 showing different DRX mechanisms: (a) DRX at twins and (b) DRX at lamellar LPSO phase within matrix grains.

At higher strain rates, twin formation played a more significant role (Figure 9). When forming began $(\varphi=0.2)$, high twinning density could already be identified in the microstructure at a strain rate of $10 \mathrm{~s}^{-1}$ (Figure 11). In the further course of the forming process, these twins could serve as initiation points for the nucleation of dynamic recrys- 
tallisation, as shown in Figure 10a. The high twinning density favoured the course of DRX, as shown previously in Figure 7. Similar results for magnesium alloys with LPSO phases are presented in $[14,33]$.

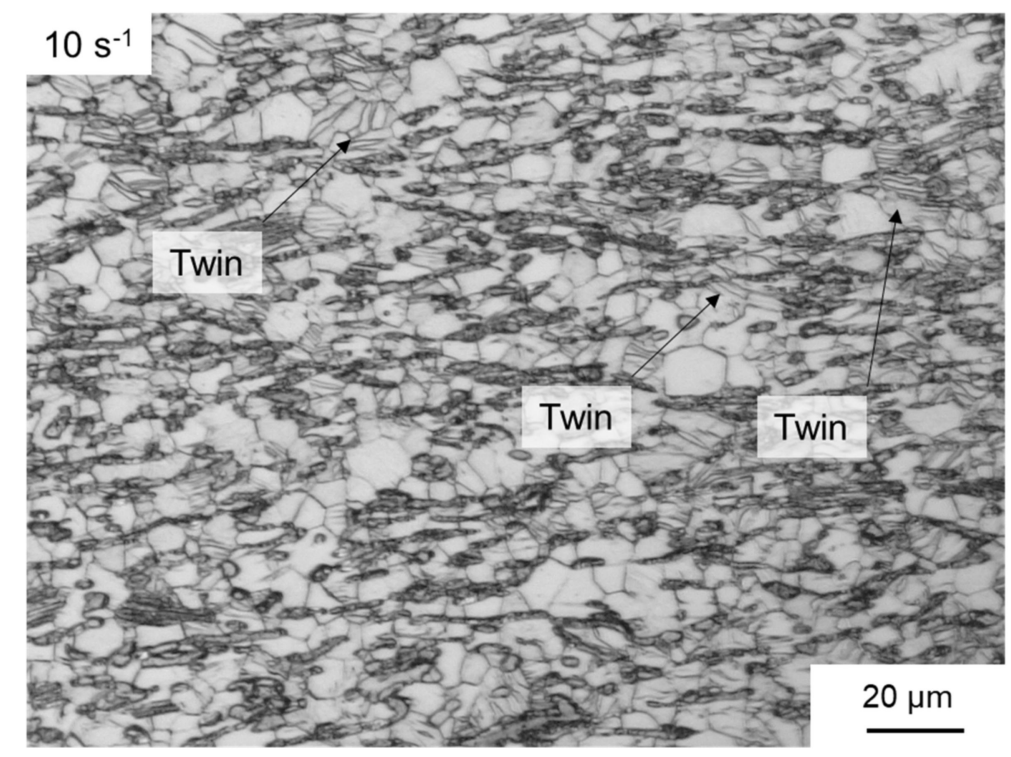

Figure 11. Optical micrograph of sample deformed at $10 \mathrm{~s}^{-1}$ and a low equivalent strain of 0.2.

\subsection{Processing Maps}

A processing map is the superimposition of a power dissipation efficiency map and the instability parameter map. The flow-stress data obtained from the hot compression tests are used to plot the processing maps using different DMM models. These maps can provide the processing window along with an opinion on deformation mechanisms that can be helpful for industrial applications. To avoid accumulation of internal energy, the processing maps are plotted for strains after strain hardening. The corresponding material parameters $m, \eta$ and $\xi$ are calculated according to [20,21]. Isolines of temperatures and strain rates are plotted on the two-dimensional plane; namely the power dissipation map and the instability map. The two processing maps based on the Prasad instability criterion are obtained by superimposing them. As shown in Figure 12, the shadow zone in the processing map is the instability zone and the coloured zone is the safe machining zone.

According to the processing map, two instability zones could be recognised: the first instability zone occurs in the temperature range of $350{ }^{\circ} \mathrm{C}$ to $460{ }^{\circ} \mathrm{C}$ and over a strainrate range of $0.01 \mathrm{~s}^{-1}$ to $0.3 \mathrm{~s}^{-1}$; the second instability zone occurs in the temperature range of $485{ }^{\circ} \mathrm{C}$ to $525^{\circ} \mathrm{C}$ and over a strain-rate range of $2.5 \mathrm{~s}^{-1}$ to $10 \mathrm{~s}^{-1}$. In these zones, the corresponding power dissipation coefficient of materials is comparatively low, and the instability of adiabatic shear bands or local plastic flow tends to occur during deformation. Cracks appeared in the alloy in these instability zones, as can be seen in the micrographs of Figure $12 \mathrm{~b}, \mathrm{c}$.

Large values of $m$ were observed at moderate to high temperatures $\left(460^{\circ} \mathrm{C}\right.$ to $\left.525^{\circ} \mathrm{C}\right)$ at strain rates of up to $2.5 \mathrm{~s}^{-1}$. Moreover, in this domain the stress value increased steadily to a peak followed by softening towards the steady-state region (see, for example, Figure 2), which is a typical observation made during DRX. This was also proved by optical micrography as shown in Figure 7, which shows recrystallised grains without any cracks, because no flow lines of the plastic deformation are observed. In addition, DRX regions are also visible when the strain rates are increased above $0.3 \mathrm{~s}^{-1}$ and the temperatures are decreased to $400{ }^{\circ} \mathrm{C}$ or $450^{\circ} \mathrm{C}$. In these ranges, the values of $m$ and $\eta$ are high, and stability is predicted. Therefore, such stable ranges offer the best processing parameters. 


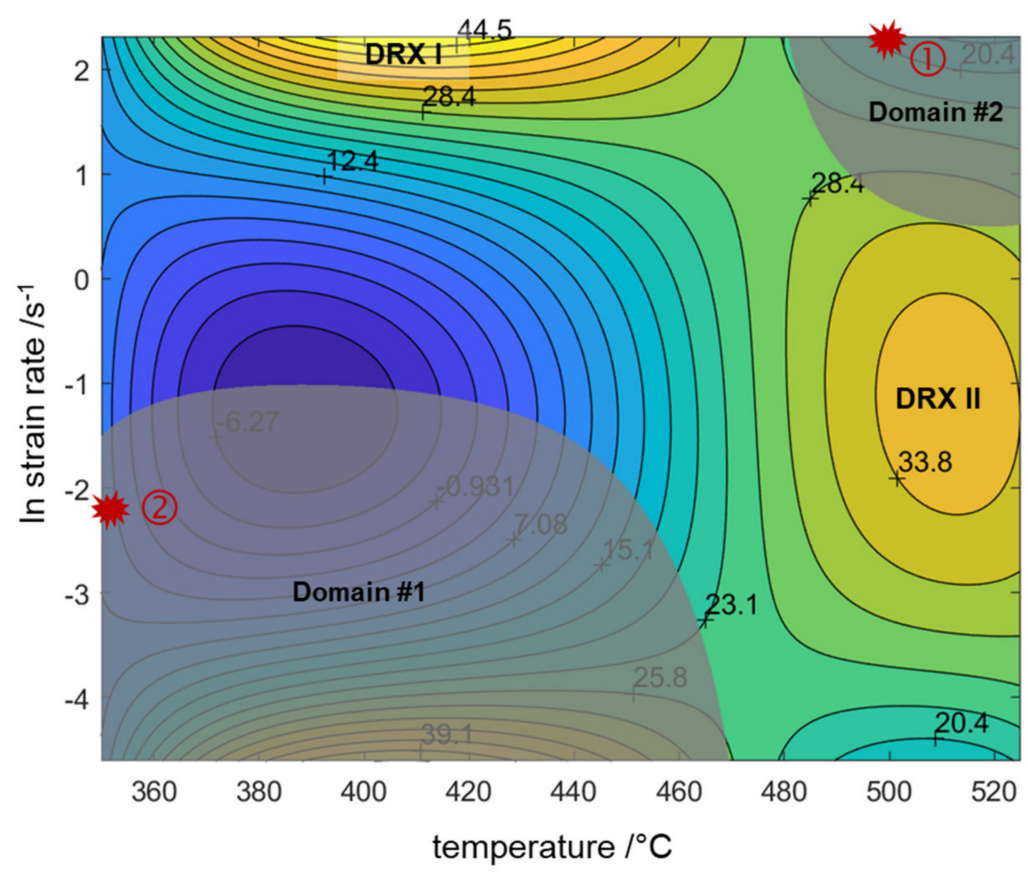

(a)

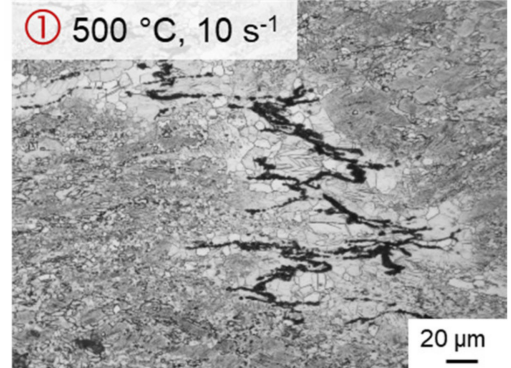

(b)

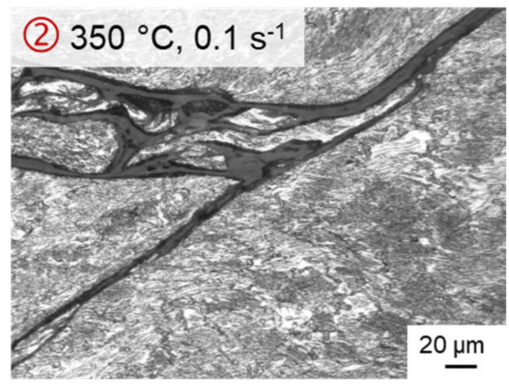

(c)

Figure 12. (a) Processing map of twin-roll cast and heat-treated Mg-6.8Y-2.5Zn-0.4Zr alloy at an equivalent strain of 0.4 and optical micrographs from areas of instability: (b) Domain \#2: $500{ }^{\circ} \mathrm{C}, 10 \mathrm{~s}^{-1}$ and (c) Domain \#1: $350{ }^{\circ} \mathrm{C}, 0.1 \mathrm{~s}^{-1}$ (red circles denote domain, where the micrographs refer to).

\section{Conclusions}

In this work, the deformation behaviour of a twin-roll cast (TRC) Mg-6.8Y-2.5Zn- $0.4 \mathrm{Zr}$ alloy during plane strain compression was characterised by high-temperature testing and the following conclusions can be drawn:

(1) It was assumed that DRX was favoured in the twin-roll cast and heat-treated Mg-6.8Y$2.5 \mathrm{Zn}-0.4 \mathrm{Zr}$ alloy. In contrast to the conventionally cast initial material, there were no lamellae precipitated in the magnesium matrix in the twin-roll cast and heat-treated initial state. Such lamellar LPSO phases can contribute to delay of the DRX process.

(2) The activation energy for the twin-roll cast and heat-treated Mg-6.8Y-2.5Zn-0.4Zr alloy was determined to be $270 \mathrm{~kJ} / \mathrm{mol}$, which was significantly higher than that for grain boundaries $(92 \mathrm{~kJ} / \mathrm{mol})$ or lattice diffusions $(135 \mathrm{~kJ} / \mathrm{mol})$ in magnesium. The higher value for the activation energy was likely associated with the increased proportion of LPSO phases.

(3) During cooling after heat-treatment temperature to the forming temperature, fine lamellae precipitated within the $\alpha$-magnesium matrix. Dynamic recrystallisation hardly occurred during forming at temperatures between $350{ }^{\circ} \mathrm{C}$ and $400{ }^{\circ} \mathrm{C}$, so that even at an equivalent strain of 1 , only a small proportion of recrystallised grains could be observed. One possible reason for this was the precipitation of lamellar LPSO phases, which contribute to the retardation of the DRX process.

(4) Several mechanisms of dynamic recrystallisation during forming of the twin-roll cast and heat-treated Mg-6.8Y-2.5Zn-0.4Zr strip could be identified. Nucleation occurred primarily at twin boundaries (twin-induced dynamic recrystallisation, TDRX). Occasionally, DRX occurred at the grain boundaries of the original microstructure, resulting in the characteristic necklace structure during continuous dynamic recrystallisation (CDRX).

(5) According to the processing map, two instability zones could be recognised: (1) $350{ }^{\circ} \mathrm{C}$ to $460{ }^{\circ} \mathrm{C}$ and $0.01 \mathrm{~s}^{-1}$ to $0.3 \mathrm{~s}^{-1}$ and (2) $485^{\circ} \mathrm{C}$ to $525^{\circ} \mathrm{C}$ and $2.5 \mathrm{~s}^{-1}$ to $10 \mathrm{~s}^{-1}$. In those areas, the corresponding power dissipation coefficient is relatively low, and also the 
instability of adiabatic shear bands or nearby plastic flow has a tendency to arise at some stage in deformation.

Author Contributions: Conceptualisation: M.U.; methodology: M.U.; formal analysis: M.U.; investigation: K.K.; resources: U.P.; data curation: M.U.; writing—original draft preparation: M.U. and K.K.; writing—review and editing: M.U. and U.P.; visualisation: M.U.; supervision: U.P.; project administration: U.P.; funding acquisition: M.U. and U.P. All authors have read and agreed to the published version of the manuscript.

Funding: The project "Saxon Alliance for Material- and Resource-Efficient Technologies (AMARETO)" is funded by the European Union (European Regional Development Fund) and by the Free State of Saxony. Grant Number: 100291457.

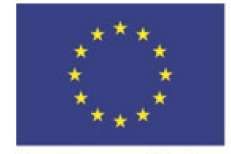

European Union

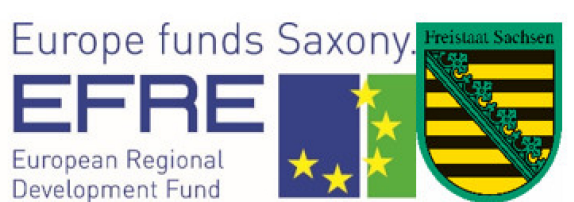

Institutional Review Board Statement: Not applicable.

Informed Consent Statement: Not applicable.

Data Availability Statement: Data sharing is not applicable to this article.

Acknowledgments: We thank Susanne Berndorf from the Institute of Metal Forming for microstructure characterisation via SEM.

Conflicts of Interest: The authors declare no conflict of interest. The funders had no role in the design of the study; in the collection, analyses, or interpretation of data; in the writing of the manuscript, or in the decision to publish the results.

\section{References}

1. Zhu, Y.M.; Morton, A.J.; Nie, J.F. The 18R and 14H long-period stacking ordered structures in Mg-Y-Zn alloys. Acta Mater. 2010, 58, 2936-2947. [CrossRef]

2. Kawamura, Y.; Hayashi, K.; Inoue, A.; Masumoto, T. Rapidly Solidified Powder Metallurgy Mg97Zn1Y2Alloys with Excellent Tensile Yield Strength above $600 \mathrm{MPa}$. Mater. Trans. 2001, 42, 1172-1176. [CrossRef]

3. Yi, J.-X.; Tang, B.-Y.; Chen, P.; Li, D.-L.; Peng, L.-M.; Ding, W. Crystal structure of the mirror symmetry 10H-type long-period stacking order phase in Mg-Y-Zn alloy. J. Alloy. Compd. 2011, 509, 669-674. [CrossRef]

4. Hagihara, K.; Okamoto, T.; Izuno, H.; Yamasaki, M.; Matsushita, M.; Nakano, T.; Kawamura, Y. Plastic deformation behavior of 10H-type synchronized LPSO phase in a Mg-Zn-Y system. Acta Mater. 2016, 109, 90-102. [CrossRef]

5. Liu, C.; Zhu, Y.; Luo, Q.; Liu, B.; Gu, Q.; Li, Q. A 12R long-period stacking-ordered structure in a Mg-Ni-Y alloy. J. Mater. Sci. Technol. 2018, 34, 2235-2239. [CrossRef]

6. Yamashita, K.; Itoi, T.; Yamasaki, M.; Kawamura, Y.; Abe, E. A novel long-period stacking/order structure in Mg-Ni-Y alloys. J. Alloy. Compd. 2019, 788, 277-282. [CrossRef]

7. Zhu, Y.M.; Morton, A.J.; Nie, J.F. Growth and transformation mechanisms of $18 \mathrm{R}$ and $14 \mathrm{H}$ in Mg-Y-Zn alloys. Acta Mater. 2012, 60, 6562-6572. [CrossRef]

8. Liu, H.; Yan, K.; Yan, J.; Xue, F.; Sun, J.; Jiang, J.; Ma, A.-B. Precipitation behavior of 14H LPSO structure in single 18R phase Mg-Y-Zn alloy during annealing at 773 K. Trans. Nonferr. Met. Soc. China 2017, 27, 63-72. [CrossRef]

9. Chuang, W.S.; Huang, J.C.; Lin, P.H.; Hsieh, C.H.; Lin, Y.H.; Takagi, K.; Mine, Y.; Takashima, K. Deformation mechanisms and mechanical properties of (0001) Mg-Zn-Y 18R-LPSO single crystals. J. Alloy. Compd. 2019, 772, 288-297. [CrossRef]

10. Abe, E.; Ono, A.; Itoi, T.; Yamasaki, M.; Kawamura, Y. Polytypes of long-period stacking structures synchronized with chemical order in a dilute Mg-Zn-Y alloy. Philos. Mag. Lett. 2011, 91, 690-696. [CrossRef]

11. Chen, T.; Chen, Z.; Shao, J.; Wang, R.; Mao, L.; Liu, C. The role of long period stacking ordered phase in dynamic recrystallization of a Mg-Zn-Y alloy during hot compression. J. Alloy. Compd. 2020, 818, 152814. [CrossRef]

12. Zhang, Z.; Yan, Z.; Du, Y.; Zhang, G.; Zhu, J.; Ren, L.; Wang, Y. Hot Deformation Behavior of Homogenized Mg-13.5Gd-3.2Y2.3Zn-0.5Zr Alloy via Hot Compression Tests. Materials 2018, 11, 2282. [CrossRef] [PubMed]

13. Li, Y.; Xiao, W.; Wang, F.; Hu, T.; Ma, C. The roles of long period stacking ordered structure and Zn solute in the hot deformation behavior of Mg-Gd-Zn alloys. J. Alloy. Compd. 2018, 745, 33-43. [CrossRef]

14. Li, K.; Chen, Z.; Chen, T.; Shao, J.; Wang, R.; Liu, C. Hot deformation and dynamic recrystallization behaviors of Mg-Gd-Zn alloy with LPSO phases. J. Alloy. Compd. 2019, 792, 894-906. [CrossRef] 
15. Xu, C.; Pan, J.; Nakata, T.; Qiao, X.; Chi, Y.; Zheng, M.; Kamado, S. Hot compression deformation behavior of Mg-9Gd-2.9Y-1.9Zn0.4Zr-0.2Ca (wt.\%) alloy. Mater. Charact. 2017, 124, 40-49. [CrossRef]

16. Shao, Z.; Zhu, X.; Wang, R.; Wang, J.; Xu, Y.; Zhao, B.; Ling, G. Hot deformation and processing map of as-homogenized Mg-9Gd-3Y-2Zn-0.5Zr alloy. Mater. Des. 2013, 51, 826-832. [CrossRef]

17. Prasad, Y.V.R.K.; Rao, K.P. Processing maps for hot deformation of rolled AZ31 magnesium alloy plate: Anisotropy of hot workability. Mater. Sci. Eng. A 2008, 487, 316-327. [CrossRef]

18. Lv, B.J.; Peng, J.; Peng, Y.; Tang, A.T.; Pan, F.S. The effect of LPSO phase on hot deformation behavior and dynamic recrystallization evolution of Mg-2.0Zn-0.3Zr-5.8Y alloy. Mater. Sci. Eng. A 2013, 579, 209-216. [CrossRef]

19. Kittner, K.; Ullmann, M.; Arndt, F.; Kawalla, R.; Prahl, U. Microstructure and Texture Evolution during Twin-Roll Casting and Annealing of a Mg-6.8Y2.5Zn-0.4Zr Alloy (WZ73). Crystals 2020, 10, 513. [CrossRef]

20. Kittner, K.; Ullmann, M.; Henseler, T.; Kawalla, R.; Prahl, U. Microstructure and Hot Deformation Behavior of Twin Roll Cast Mg-2Zn-1Al-0.3Ca Alloy. Materials 2019, 12, 1020. [CrossRef]

21. Ullmann, M.; Schmidtchen, M.; Kittner, K.; Henseler, T.; Kawalla, R.; Prahl, U. Deformation Behaviour of an as-Cast Mg6.8Y-2.5Zn-0.3Zr Alloy during Hot Compression. In Proceedings of the MEFORM 2019, Freiberg, Germany, 20-21 March 2019.

22. Ullmann, M.; Schmidtchen, M.; Kawalla, R. Dynamic Recrystallization Behaviour of Twin Roll Cast AZ31 Strips during Hot Deformation. Key Eng. Mater. 2014, 622, 569-574. [CrossRef]

23. Xia, X.; Chen, Q.; Huang, S.; Lin, J.; Hu, C.; Zhao, Z. Hot deformation behavior of extruded Mg-Zn-Y-Zr alloy. J. Alloy. Compd. 2015, 644, 308-316. [CrossRef]

24. Xu, C.; Nakata, T.; Qiao, X.; Zheng, M.; Wu, K.; Kamado, S. Effect of LPSO and SFs on microstructure evolution and mechanical properties of Mg-Gd-Y-Zn-Zr alloy. Sci. Rep. 2017, 7, 40846. [CrossRef] [PubMed]

25. Garofalo, F. Fundamentals of Creep and Creep-Rupture in Metals; McMillan Series in Materials Science; McMillan: New York, NY, USA, 1965.

26. Weertman, J. Dislocation climb theory of steady-state creep. ASM Trans. Quart. Metal Sci. 1968, 61, 681-694. [CrossRef]

27. González, S.; Pérez, P.; Garcés, G.; Adeva, P. Influence of the processing route on the mechanical properties at high temperatures of Mg-Ni-Y-RE alloys containing LPSO-phases. Mater. Sci. Eng. A 2016, 673, 266-279. [CrossRef]

28. Kim, W.-J.; Chung, S.W.; Chung, C.S.; Kum, D. Superplasticity in thin magnesium alloy sheets and deformation mechanism maps for magnesium alloys at elevated temperatures. Acta Mater. 2001, 49, 3337-3345. [CrossRef]

29. Frost, H.J.; Ashby, M.F. Deformation-Mechanism Maps: The Plasticity and Creep of Metals and Ceramics; Pergamon Press: Oxford, UK, 1982.

30. Yang, Z.; Ye, H.Z. Strengthening mechanisms in Mg97Zn1Y2 alloys. In Magnesium Technology; Springer: Cham, Switzerland, 2015; pp. 295-299.

31. Bae, D.H.; Kim, S.H.; Kim, D.H.; Kim, W.T. Deformation behavior of Mg-Zn-Y alloys reinforced by icosahedral quasicrystalline particles. Acta Mater. 2002, 50, 2343-2356. [CrossRef]

32. Kwak, T.Y.; Lim, H.K.; Kim, W.J. Hot compression behavior of the ignition-resistant Mg-5Y-2.5Zn-1.2Ca alloy with long-period stacking ordered structures. J. Alloy. Compd. 2015, 632, 417-428. [CrossRef]

33. Lv, B.-J.; Peng, J.; Zhu, L.-L.; Wang, Y.-J.; Tang, A.-T. The effect of $14 \mathrm{H}$ LPSO phase on dynamic recrystallization behavior and hot workability of Mg-2.0Zn-0.3Zr-5.8Y alloy. Mater. Sci. Eng. A 2014, 599, 150-159. [CrossRef]

34. Chen, Y.J.; Wang, Q.D.; Roven, H.J.; Liu, M.P.; Karlsen, M.; Yu, Y.D.; Hjelen, J. Network-shaped fine-grained microstructure and high ductility of magnesium alloy fabricated by cyclic extrusion compression. Scr. Mater. 2008, 58, 311-314. [CrossRef] 